\title{
The importance of the size of the digital dividend when digital dividend spectrum is auctioned
}

\author{
José Luis Gómez-Barroso* \\ and Asunción Mochón
}

Departamento Econonía Aplicada e Historia Económica, UNED - Universidad Nacional de Educación a Distancia,

$P^{\circ}$ Senda del Rey, 11. 28040, Madrid, Spain

E-mail: jlgomez $(\bar{a})$ cee.uned.es

E-mail: amochon $(a)$ cee.uned.es

${ }^{*}$ Corresponding author

\section{Yago Sáez}

Departamento de Inteligencia Artificial.

Universidad Carlos III de Madrid,

Avda. de la Universidad, 30 . Edificio Sabatini,

28911 Leganés, Madrid, Spain

E-mail: yago.saez(âuc3m.es

\section{Claudio Feijóo}

CeDInt. Universidad Politécnica de Madrid.

Campus de Montegancedo.

28223 Pozuelo de Alarcón. Madrid. Spain

E-mail: cfeijoo $a$ cedint.upm.es

\begin{abstract}
This paper simulates a 'service-neutral' digital dividend auction, considering three different amounts of spectrum $(48 \mathrm{MHz}, 80 \mathrm{MHz}$ and $120 \mathrm{MHz}$ ). For this, an efficient simulator for combinatorial first-price sealed bid anctions has been implemented. The results show rather coherently that the price per lot is higher the smaller the amount of spectrum auctioned and that companies from the mobile environment will most probably emerge as main winners from these digital dividend auctions. These research findings are particularly important as the sharing out of the digital dividend represents a unique opportunity for putting a precious amount of radio electric spectrum at the disposal of other services, particularly for the development of new generations of mobile communications.
\end{abstract}

Keywords: digital dividend; spectrum auctions; spectrum management; digital switchover, combinatorial auctions; UHF band; mobile communication: television; digital broadcasting; mobile multimedia.

Reference to this paper should be made as follows: Gomez-Barroso, J.L., Mochón, A., Sáez, Y. and Feijóo, C. (2011) 'The importance of the size of the digital dividend when digital dividend spectrum is auctioned', Int. J. Mobile Communications, Vol. 
Biographical notes: José Luis Gómez-Barroso is an Associate Professor at Universidad Nacional de Educación a Distancia (UNED). He holds a PhD and a Degree in Economics from the Universidad Nacional de Educación a Distancia (UNED). He also holds a Degree in Telecommunication Engineering from the Universidad Politécnica de Madrid as well as another Degree in Law from the Universidad Complutense. He has participated in different research projects, some of them for the European Commission. Presently, he is a member of the Management Committee of the COST 605 Action (Econ $(a)$ Tel - A Telecommunications Economics COST Network).

Asunción Mochón holds a Degree in Economics by Universidad Autónoma de Madrid and a $\mathrm{PhD}$ from UNED, where she is currently an Associate Professor at the Department of Applied Economics. Her research focuses on auctions in several markets, like spectrum licences. Most of her recent works have addressed key questions in multiunit auctions and combinatorial auctions. To this end, evolutionary computation techniques, like genetic algorithms, have been tested in several auctions models. She has published several papers on auctions in major journals and congresses.

Yago Sáez received the Computer Engineering Degree from the Universidad Pontificia de Salamanca, Spain, in 1999. He got his $\mathrm{PhD}$ in Computer Science from the Universidad Politécnica de Madrid, Spain, in 2005. Nowadays, he works as an Associate Professor in the University Carlos III of Madrid, Spain. $\mathrm{He}$ is member of the Evolutionary Computation. Neural Networks and Artificial Intelligence group (EVANNAI) and takes part of the IEEE Computational Finance and Economics Technical Committee. His main research areas encompass the evolutionary computation, the computational economic and finance applications and the optimisation by means of metaheuristics.

Claudio Feijoo is a Professor at Universidad Politécnica de Madrid where he researches on the future socio-economic impact of emerging information society technologies. He has just come back from a highly rewarding two years' visiting research at the Institute for Prospective Teclunological Studies of the European Commission. Since 1993, he has been involved in telecommunications and information society development from the academia, the practical implementation and the public administration perspectives.

$\mathrm{He}$ lectures regularly on these matters and has published more than 50 peer-reviewed papers in academic journals and books.

\section{Introduction}

The concept of 'digital dividend' is well known: digitising analogue terrestrial television broadcasting makes possible to free up a sizeable quantity of spectnum for potentially new services. The importance of the digital dividend is obvious. Although the radio electric spectnum has always been a scarce resource, it seems to be even more so when the users' demand for access to contents and applications moves towards a scenario characterised by broadband and ubiquity. And when as a consequence. companies require spectnum to commercially develop new generations of wireless/mobile communications with which to satisfy this pressing demand.

Regulators around the world certainly have their eyes on this spectnum. Concrete plans for how to use the digital dividend are being drawn up or have been 
already setting up. The USA has led the way in freeing up and allocating the digital dividend spectrum. On 18 March 2008, the Federal Communications Commission (FCC) completed the auction of 1099 licences in the $700 \mathrm{MHz}$ band. imaginatively called 'beachfront spectrum'. The FCC allowed the spectrum to be used on 'technology neutral grounds'.

The list of countries that could make a similar decision will grow as the switchover from analogue to digital terrestrial television is completed. In Germany, the majority of funds raised from the spectrum auction that came to an end on 20 May 2010 were earmarked for $800 \mathrm{MHz}$ frequency (digital dividend) licences. Some other European countries have already made public plans in this direction, with the UK (its regulator, Ofcom) being the one that seems to have progressed the most as regards the procedures prior to the auction.

The exact calculation of how much spectrum could be auctioned depends on the particular digital broadcasting technology that is used and on the specific characteristics of the broadcast area. But, more important than the above, at the end of the day this is a political decision. Almost all governments that have already decided how to carry out the digital switchover have believed it appropriate to provide capacity for some additional broadcasting services. How much spectrum 'remains' for other uses or services is, therefore, more of a decision than a calculation. Undoubtedly, knowing how the results of a hypothetical auction would vary depending on the amount of spectrum available for allocation would be quite an interesting datum for any government considering what decision they should make.

This is precisely the objective of this paper: it simulates three service-neutral digital dividend auctions considering three different amounts of spectrum. In view of the assumptions made in the model, it can be considered that the simulation is orientative for a major-type European country. However, the aim of the paper is not so much to obtain exact estimations of the results of the auction (something that is obviously quite complicated) as to compare the different modelled situations. Therefore, the generic conclusions can be valid for any other country.

The paper is structured as follows: Section 2 presents literature review on the three most important topics for the paper: the digital dividend itself, the services to which the dividend can be assigned and the use of auctions as the method to allocate spectrum. Section 3 globally describes the current situation of the analogue blackout and the decisions about the size of the digital dividend. Section 4 presents the methodology and the parameters of the model that have been used. Section 5 discusses the results obtained. The conclusions close the paper.

\section{Related work}

Three are the immediate questions that can be asked as regards the digital dividend: How much spectrum is (should be) freed-up as well as which services will be allocated to and how?

\subsection{About the size of the digital dividend}

The digital dividend is derived by the ability of digital compression systems to allow the transmission of several standard digital television channels in the spectnum previously 
used by one analogue channel while maintaining or improving quality of video and audio. Ofcom (2006) states that "digital broadcasting is roughly six times more efficient than analogue, allowing more channels to be carried across less spectrum". Given that television broadcasting in Europe occupies $392 \mathrm{MHz}$ of the UHF band (channels $21-69$; $470-862 \mathrm{MHz}$ ), the dividend would exceed $300 \mathrm{MHz}$.

Much more precise in its calculations is the report requested by the European Commission and published in April 2002 (BIPE Consulting. 2002). This study quantifies the digital dividend that would result from using the DVB-T standard for digital television without considering high-definition broadcasting. It is considered that five to ten $8 \mathrm{~Hz}$ channels are required to broadcast an analogue television programme throughout a whole country without any risk of interference. With digital transition, those $8 \mathrm{MHz}$ that were previously occupied by one channel could be used for a 'multiplex' and, depending on the assumptions made for the transmission and the reception, 3-15 channels would be required for national coverage. Operating with these parameters, the dividend would fluctuate between $272 \mathrm{MHz}$ and $368 \mathrm{MHz}$.

Although old, this calculation seems to maintain its validity since in the much more recent report that the European Commission has requested for preparing their recommendation on the digital dividend (Analysys Mason et al., 2009), the theoretical dividend is still estimated in around $320 \mathrm{MHz}$. Despite the above, it must be noted that the gain will be even more substantive if more advanced standards are introduced (such as DVB-T2 for infrastructure and MPEG-4 for compression) or if further spectrum efficiency gains are achieved.

Television channel frequencies are different in other geographical areas, but in most countries, analogue television occupies (occupied) amounts of around $400 \mathrm{MHz}$ of the UHF band, making the calculation of the theoretical dividend comparable in very broad terms with that of the European countries.

However, as stated in the introduction, the answer to this first question has a political side as important as the technical side. Almost all governments are reserving part of the theoretical digital dividend spectrum to provide capacity for additional broadcasting services. Section 3 gives a global overview of the decisions made regarding how much spectrum is being freed-up.

\subsection{About the possible uses of the digital dividend}

Almost all service and application providers using the radio electric spectrum would be interested in participating in the sharing out of this 'newly available' spectrum. The digital dividend spectrum fall within the UHF band, which, as regards other frequencies, presents a series of characteristics that provide an appealing balance between distance coverage and transmission capability. Additionally, the low signal attenuation in the presence of obstacles guarantees adequate coverage inside buildings without the need for additional equipment, thus minimising the infrastructure costs required for deployment.

Therefore, the list of possible services the digital dividend could be allocated to is long: digital terrestrial television, mobile multimedia, mobile communications, low power device-related services such as medical telemetry, Radio Frequency Identification (RFID) or Near Field Communications (NFCs); non-commercial services such as defence, security, emergencies or other public services, or even services yet to be fully developed 
It should not be forgotten that, as pointed out in the introduction, companies require spectrum to commercially develop new or improved mobile services that consumers value and are willing to pay for (refer to interesting case studies in Liu et al. (2008) and Chong et al. (2010)). Particularly, mobile broadband is proving popular with both business and residential users and it will become increasingly popular as diffusion barriers are gradually overcome (Karaiskos et al., 2008; Kim et al., 2009).

\subsection{About the method to allocate the digital dividend spectrum}

As regards how the spectrum should be allocated, the decision regarding the dividend appears in a time of change as regards radio electric spectrum management (Feijóo et al., 2009). A current of opinion favourable to the introduction of market econony criteria seems to be consolidating (Bykowsky et al., 2010). One of the key aspects of this reform is precisely the use of auctions as the preferred licence-allocation mechanism.

The usage of auctions is, however, not at all unknown in the sector. Licences have been auctioned for years and in a great deal of countries. However, there was a point of inflection in the consideration of auctions as a spectrum-allocation mechanism. During 2000 and 2001, several European countries auctioned third generation (3G or UMTS) mobile-communications licences (see an analysis in Melody (2001)). The amount reached by the bids even led the spectrum auctions to make the headlines in the media. Since then, researches on auctions started proliferating, attempting to reach the optimum allocation mechanisms for the spectrum in terms of efficiency as well as of revenue maximisation (Banks et al., 2003; Plot and Salmon, 2004; Bajari and Yeo, 2009; Wang and Barnes, 2009). Failures and successes of the recent FCC's $700 \mathrm{MHz}$ auction have already been analysed ex-post (Bazelon, 2009).

\section{The size of the digital dividend in practice}

The USA switched off analogue TV on 12 June 2009. The digital dividend released was of $108 \mathrm{MHz}$ in the $698-806 \mathrm{MHz}$ band (the " $700 \mathrm{MHz}$ band"). $24 \mathrm{MHz}$ of this spectnim were set aside for public safety systems. and $22 \mathrm{MHz}$ had been auctioned to allow new commercial uses such as mobile television (auctions 44 and 49). Through the famous "auction 73", the FCC auctioned the remaining $62 \mathrm{MHz}$. beginning on 24 January 2008 and ending on 18 March 2008. Auction 73 offered a total of 1099 licences sold in five blocks: block A and B $-2 \times 6 \mathrm{MHz}$; block $\mathrm{C}-2 \times 11 \mathrm{MHz}$; block $\mathrm{D}-2 \times 5 \mathrm{MHz}$; block $\mathrm{E}-6 \mathrm{MHz}$ unpaired.

Initially, the switchover from analogue to digital terrestrial TV has to be completed in Europe by the end of 2012. Within this deadline, each country is following a different pace towards the switchover and a different approach to the dividend. 'Group A' countries have already completed the switchoff: Finland, Germany, Luxembourg, the Netherlands, Sweden and the region of Flanders in Belgium. The Group B, which has the switchoff date at end-2010 or earlier, includes Austria, Denmark, Estonia, Malta, Slovenia and Spain. The rest ('Group C') aims at the period between end-2010 and end-2012. Only Poland has been given a farther switchoff deadline, i.e., 2015 at the latest. 
In October 2009, the Conmission adopted a Recommendation in which asks EU Member States to speed up the switchoff of analogue TV (to complete it by 1 January 2012) and to set aside one part of the freed-up spectrum, namely the $790-862 \mathrm{MHz}$ sub-band, to support the emergence of new wireless services. Germany became the first country to follow the recommendation. In May 2010, spectrum in several frequency bands $(800 \mathrm{MHz}, 1.8 \mathrm{GHz}, 2 \mathrm{GHz}$ and $2.6 \mathrm{GHz})$ was auctioned; it was airwaves in the digital dividend band $(6 \times 5 \mathrm{MHz}$ paired blocks in the $791-821 \mathrm{MHz}$ and $832-862 \mathrm{MHz})$ that was most sought after and commanded the highest fees. Several other Member States have already announced plans for the digital dividend. In the UK. $112 \mathrm{MHz}$ is being earmarked for open auctions. Sweden had earmarked $152 \mathrm{MHz}$ for opening up but stepped back to re-allocate only $72 \mathrm{MHz}$ in the first wave. France has advanced plans similar to those in Sweden.

Japan's switchover is planned for July 2011. In Japan. $60 \mathrm{MHz}$ of UHF spectrum ( $710-770 \mathrm{MHz})$ have already been earmarked for re-allocation. This spectrum may be awarded by technology-neutral auctions.

South Korea has planned the switchoff of analogue television for end-2012. This will initially free up the $54 \mathrm{MHz}$ between 752 and $806 \mathrm{MHz}$. The future use of this spectrum has yet to be decided.

Australia has released. in January 2010. a Digital dividend Green Paper. Analogule television transmission will be progressively turned off from 2010 with a complete switchover to digital television transmission by December 2013. The Green Paper proposes a dividend of $126 \mathrm{MHz}$, most likely at $694-820 \mathrm{MHz}$.

Other countries are still at an earlier stage in planning digital switchover: New Zealand's switchover date remains vague. sometime between 2013 and 2015 : China. India and Russia target 2015: Brazil. mid-2016. Consequently, they have not yet identified exactly how much spectrum, if any. will be released.

\section{Characteristics of the model}

\subsection{Methodology}

The model aims to simulate a digital dividend auction that could fit in a major-type European country. It was set up as described in the following subsections. Once defined the model, an efficient simulator for combinatorial first-price sealed bid auctions has been implemented. Each of the scenarios has been run 100 times.

The main computational challenge that the simulator must solve is the winner determination problem. Combinatorial auctions have an intrinsic computational problem: finding a feasible combination of bids, which maximises the auctioneer's revenue, i.e., solving the winner determination problem. As the number of bids, bidders and items increases, the problem becomes more complex. In this model, to work out the winner determination problem, an $\mathrm{A}^{*}$ search algorithm (Hart et al., 1968) has been developed. The $\mathrm{A}^{*}$ tree representation used is based on a Branch On Bids $(\mathrm{BOB})$ formulation with a simple but efficient heuristic function based on revenues (for a further understanding of this algorithm, see Sáez et al. (2008)).

Other prior research has simulated bidding behaviour in auctions (Stone et al., 2003; Reeves et al., 2005; Avenali and Bassanini, 2007). However, these works are aimed at assessing particular tools or techniques and not at predicting results of real auctions. 
As far as we know, this work is the first attempt to simulate a spectrum auction under modelled conditions as real as possible.

\subsection{Spectrum to be auctioned}

Considering the different sizes of digital dividends around the world, three different scenarios have been defined: digital dividend is $48 \mathrm{MHz}, 80 \mathrm{MHz}$ or $120 \mathrm{MHz}$. This spectrum is divided into lots of $8 \mathrm{MHz}$ each. That means 6,10 or 15 lots to be auctioned. The division into $8 \mathrm{MHz}$ channels has two reasons:

- it is the size of the existing television channels in Europe and, therefore, simplifies spectrum management and equipment operation

- the Geneva-06 Agreement allocated the digital dividend spectrum in $8 \mathrm{MHz}$ channels across Europe for other uses compatible with digital broadcasting.

Service and technology neutrality has been chosen as the main constituent of the auction and, as a consequence. the lots are not preallocated to any service.

The licences are awarded for national coverage. It is more spectrally efficient. in general, to allocate spectnum across the country as a whole rather than at a more granular level (it avoids the need for additional frequencies for potentially interfering services). Additionally. it is more realistic to think that the participants in an auction will be interested in providing national services (except for local or regional television. which it is not considered in the model).

\subsection{Type of auction}

A combinatorial first-price sealed bid auction without reserve price will be used. For this auction format, bidders are allowed to submit in one single round as many bids as they wish for any combination of available lots. Then, the auctioneer determines the combination of feasible bids that maximises the revenues, i.e., solves the so-called winner determination problem. After that, winners have to pay what they bid for the awarded items.

In this way, combinatorial auctions solve the so-called 'aggregation risk' (or 'exposure problem'), which participants face when every licence is sold separately (be it in sequence or simultaneously) and the 'necessary minimum' number of lots is not won. Combinatorial auctions are then particularly appropriate if there are strong complementarities between licences (synergies) as well as substitution possibilities (see Cramton, 2007). Moreover, this auction model is fast, transparent and not prone to the appearance of collusion among the participants.

To simplify the calculations, we consider that the auctionable goods are completely homogeneous, which is approximately true in this case (frequencies are close enough to consider that the lots are close substitutes). We also consider that the valuations are equal regardless of the lots being contiguous or not. This generic approach is used in real auctions as it simplifies the process for bidders, who only have to express the number of lots they want at a particular price. The seller can then organise a follow-up process to actually allocate spectrum in such a way that, for example, as much contiguous spectrum as possible can be guaranteed. 


\subsection{Agents participating in the auction}

As stated in Section 2.2, the list of possible services the digital dividend could be allocated to is long. However, in a conmercial auction such as the one to be simulated (with licences awarded for a national coverage and $8 \mathrm{MHz}$ lots), only the three first mentioned services could have actual possibilities of obtaining spectrum:

- additional digital television channels (standard or high definition)

- multimedia services (interactive television. on-demand video. music. radio) for mobile devices

- mobile communications (voice transmission and broadband connection for data transmission)

As a consequence, the participation in the auction is restricted to companies interested in operating in these markets. We establish a total of 15 participants in the auction: eight previously present in any of these markets and seven newcomers. Their characteristics are described here:

- Digital television broadcasters (four).

Their interest is to obtain more spectrum for broadcasting new digital television channels. be they standard (DTT-SD) or high definition (DTT-HD) (and in one of the cases, both types simultaneously). Additionally, one of these companies is attempting to also enter the mobile multimedia market (Mob MMedia).

- Mobile communications operators (four).

We consider two possibilities: two agents already hold spectrum in the $900 \mathrm{MHz}$ band (they are the current holders of the first GSM licences awarded) and the other two do not have any spectrum in this band (they have accessed the market more recently).

Since the four of them are already present in the market, we assume that the additional spectrum would be allocated both to voice and data services (Mob Comm Voice + Data), although we suppose that one of the agents is particularly interested in strengthening their mobile broadband access (Mob Comm Data centric). Additionally. two of these companies are interested in including also multimedia services (Mob MMedia) as a part of their offer.

- Newcomers (seven).

We consider that they only compete for entering into one of the aforementioned markets.

Table I summarises the characteristics of these participants in the auction. In the "Level of confidence" column. there are three possibilities (low-medium-high). which correspond with the perception of the possible profitability that the awarded spectrum would provide. The following section explains this in further detail. Likewise, that same section explains the contents of the 'Lots required' column. 
Table 1 Agents participating in the auction

\begin{tabular}{|c|c|c|c|c|}
\hline & Company & Tanget market & Level of confidence. & Lots required \\
\hline Bl & \multirow{4}{*}{$\begin{array}{l}\text { TV } \\
\text { broadcasters }\end{array}$} & DTT - SD & Medium & $3-12$ \\
\hline $\mathrm{B} 2$ & & $\mathrm{DTT}-\mathrm{HD}$ & Medium & $3-15$ \\
\hline B3 & & DTT - SD/DTT - HD & Low/Low & $3-15$ \\
\hline B4 & & DTT - SD/Mob Mmedia & Low/Medium & $1-15$ \\
\hline B5 & \multirow{4}{*}{$\begin{array}{l}\text { Mobile } \\
\text { operators }\end{array}$} & Mob Comm (Voice + Data) & Low & $1-8$ \\
\hline B6 & & Mob Comm (Voice + Data)/Mob MMedia & Low/Medium & $1-14$ \\
\hline B7 & & Mob Comm (Voice + Data)/Mob MMedia & High/Low & $1-14$ \\
\hline B8 & & $\begin{array}{l}\text { Mob Comm (Voice + Data)/Mob Comm } \\
\text { (Data centric) }\end{array}$ & Higl/Low & $1-15$ \\
\hline B9 & & $\mathrm{DTT}-\mathrm{SD}$ & High & $3-12$ \\
\hline $\mathrm{B} 10$ & & $\mathrm{DTT}-\mathrm{HD}$ & High & $3-15$ \\
\hline \multirow{3}{*}{\multicolumn{2}{|c|}{$\begin{array}{l}\text { B11 } \\
\text { B12 New } \\
\text { B13 entrants }\end{array}$}} & Mob Comm (Voice + Data) & High & $1-8$ \\
\hline & & Mob Comm (Data centric) & Medium & $1-8$ \\
\hline & & Mob Comm (Data centric) & High & $1-8$ \\
\hline B14 & & Mob Mnedia & Low & $1-6$ \\
\hline B15 & & Mob Mmedia & High & $1-6$ \\
\hline
\end{tabular}

\subsection{Spectrum assessments carried out by the bidders}

In the Ofcom document that consults on the proposed approach to the awarding of the digital dividend spectrum (Ofcom, 2006), there are assessments on the value that a certain additional fraction of spectrum could have for different services. These figures have been obtained as a result of a model that intends to identify the incremental producer and consumer value, which is generated by using the available UHF spectrum compared with other alternatives (other spectrum bands or delivery platforms). What is provided is the private value: the sum of industry producer surplus (profits) and consumer surplus (individual's willingness to pay in excess of the market price). The model was refined and actualised in Ofcom (2007). See details in Annex I.

As said earlier, the difficulties of an analysis of this nature are obvious. Ofcom itself assumes the limitations of the calculations:

$$
\begin{aligned}
& \text { "the high level of uncertainty and the complexity of some of the } \\
& \text { inter-relationships between services mean that this type of modelling can at } \\
& \text { best provide an order of magnitude assessment of value." }
\end{aligned}
$$

It is also obvious that none of the figures quoted in the document can be taken directly as an indication of auction proceeds. However. after being submitted to certain adaptations, they are valid for their use in a simulation exercise as the one we intend to perform. The adaptations carried out to transform them into spectrum valuations (valuations. not bids) by the participating companies are as follows:

- The total surplus is divided in equal share $(50 / 50)$ between consumers and producers. 
- For each service, Ofcom designs two scenarios: high and low value scenario. In our model, it translates into the maximum (a) and minimum (b) of the valuations bracket.

Within this bracket, three intervals are designed, which would correspond to different assessments (or confidence levels as regards the future profitability) carried out by the agents: low $[a ;(a+b) / 2]$; medium $[(3 a+b) / 4 ;(a+3 b) / 4]$; high $[(\mathbf{a}+\mathbf{b}) / 2 ; \mathbf{b}]$. Note therefore that the valuation of each agent is no longer a single value but that it can take any value within one of the above-mentioned intervals.

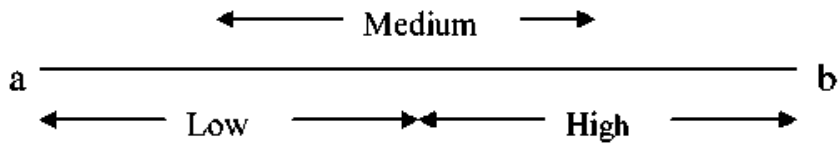

- The valuations given refer to an optimum amount of spectrum, which is specified in (or can be deduced from) the scenarios designed for each service by Ofcom. For each agent, this will be the optimal amount of lots they compete for. Higher or lower amounts are 'corrected' by a coefficient, which is higher the further away it is from the optimal value (refer to Annex I). In economic terms, this means that complementary and substitution effects between lots simultaneously exist. Goods are substitutes (subadditive values) if earning one item reduces the value of earning more items; goods are complements (superadditive values or synergies) if already having one item increases the value of awarding another one (Ausubel et al., 1997). Additionally, for some services there exists a minimum amount of lots (the service cannot be provided with less lots) or a maximum amount of lots (additional lots would be unnecessary under the current market conditions).

\subsection{Bids submitted by the bidders}

To move from valuations to actual bids, two additional steps are required. First, the exact value given by each participant is determined in each experiment by fitting a Gaussian distribution to the valuation interval. This value is the maximum players should be willing to bid in an auction. The second step is to select a 'strategy' for the bid. This is done selecting a value between 0 and 1 , again using a Gaussian distribution, for each agent and experiment. The final bid is then calculated as the product of the value and the strategy selected.

\section{Results of the experiments}

Annex II provides a comprehensive perspective of the results.

Table 2 provides a comparison of the seller income in each of the three scenarios (as an average of the 100 experiments). It can be observed that the average income per lot is higher the smaller the number of lots $(17 \%$ more in the 6 lots case when compared with the 15 lots). However, the differences between scenarios B and C (10 and 15 lots) are not too big. 
Table 2 Seller's average income $(€ \mathrm{M})$

\begin{tabular}{lccrc}
\hline & & \multicolumn{3}{c}{ Total } \\
\cline { 4 - 5 } Scenario & $M H z$ & Lots & Total & Per lot \\
\hline A & 48 & 6 & 904.6 & 150.8 \\
B & 80 & 10 & 1343.7 & 134.4 \\
C & 120 & 15 & 1927.6 & 128.5 \\
\hline
\end{tabular}

Table 3 shows (in percentage) the sharing out of the spectrum auctioned among the participants and what payment is associated to receiving said spectrum. The first observation that can be made is that four of the bidders (B1, B3, B5 and B9) do not obtain spectrum in any of the 300 experiments ( 100 per scenario). This fact, added to the scarce weight of the B2 and B10 bidders, can lead to the conclusion that the agents coming from the "television environment" do not have many possibilities in the auction as opposed to those coming from the "mobile environment". The exception is bidder B4, although in this case, their result is explained by their intention of entering the mobile multimedia market and of valuing the spectrum accordingly.

Table 3 Lots won and payment required - per bidder (aggregated results from 100 repetitions)

\begin{tabular}{|c|c|c|c|c|c|c|c|c|c|c|c|c|}
\hline \multicolumn{2}{|c|}{ Scenario } & $\begin{array}{c}B 2 \\
(\%)\end{array}$ & $\begin{array}{c}B 4 \\
(\%)\end{array}$ & $\begin{array}{c}B 6 \\
(\%)\end{array}$ & $\begin{array}{c}B 7 \\
(\%)\end{array}$ & $\begin{array}{c}B 8 \\
(\%)\end{array}$ & $\begin{array}{l}B 10 \\
(\%)\end{array}$ & $\begin{array}{l}B 1 / \\
(\%)\end{array}$ & $\begin{array}{l}B / 2 \\
(\%)\end{array}$ & $\begin{array}{l}B / 3 \\
(\%)\end{array}$ & $\begin{array}{l}B 14 \\
(\%)\end{array}$ & $\begin{array}{l}B 15 \\
(\%)\end{array}$ \\
\hline \multirow[t]{2}{*}{$\bar{A}$} & Lots & 0 & 21.5 & 22.3 & 5.7 & 1.5 & 0 & 0.8 & 1.2 & 8.2 & 3.7 & 35.2 \\
\hline & Payment & 0 & 21.1 & 22.3 & 4.2 & 0.9 & 0 & 0.5 & 0.8 & 6.4 & 2.6 & 41.3 \\
\hline \multirow[t]{2}{*}{ B } & Lots & 0 & 19.4 & 16.5 & 7.5 & 3.7 & 1.3 & 2.6 & 4.3 & 9.8 & 7.3 & 27.6 \\
\hline & Payment & 0 & 20.3 & 17.0 & 6.1 & 2.3 & 0.8 & 1.6 & 3.4 & 8.5 & 6.1 & 33.9 \\
\hline \multirow[t]{2}{*}{$\mathrm{C}$} & Lots & 0.5 & 14.4 & 16.3 & 9.7 & 4.7 & 2.9 & 3.5 & 5.9 & 13.7 & 7.1 & 21.4 \\
\hline & Payment & 0.3 & 15.8 & 17.4 & 8.4 & 3.5 & 2.2 & 2.5 & 4.8 & 12.3 & 5.7 & 27.1 \\
\hline
\end{tabular}

Built upon the results of Table 3, Figure 1 shows more clearly the evolution of the results as regards the number of lots won. It can be observed that the spectrum is increasingly shared out among the different bidders the greater the amount of spectrum is offered. Thus, in Scenario A (auction of 6 lots), three bidders $(4,6$ and 15$)$ win almost $80 \%$ of the lots. Their weight decreases in the other scenarios and in the case of Scenario C (15 lots) they only exceed slightly $50 \%$, despite the average price paid per lot by these three strong bidders is still greater than that paid by the remaining bidders that obtain spectrum

Figure 1 Lots won - Per bidder (aggregated results from 100 repetitions) (see online version for colours)

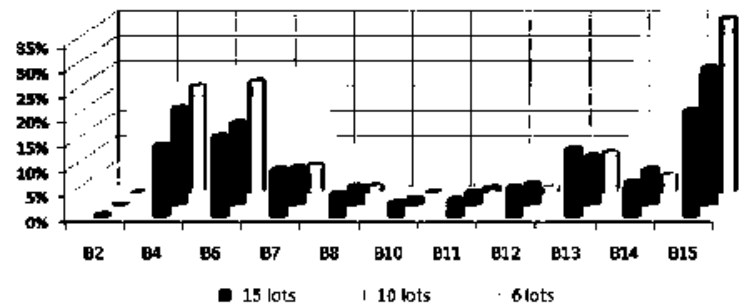

Horizontal axis shows bidder identifier (from B1-B15) - Refer to Table 1.

Vertical axis is the percentage distribution of lots. 
It must also be noted that in scenario A (six lots), the results are less certain both for the auctioneer and for the bidders. Indeed, the standard deviation of the auction income represents, in this case, $15.6 \%$ of the average (for $12.7 \%$ in scenario $\mathrm{B}$ and $11.3 \%$ in scenario $\mathrm{C}$ ) while the minimum income obtained in the 100 experiments represents $58.7 \%$ of the average (as opposed to $69.4 \%$ and $68 \%$, respectively). As regards the participants in the auction, we can take the case of bidder 15 (strongest bidder) as an example. Annex II shows that the number of times that bidder 15 wins zero lots in scenario $\mathrm{A}$ is 27 (across 100 experiments) and in 5 occasions they obtain a single lot. In scenario $B$, these figures are 17 and 3 ; in $\mathrm{C}, 13$ and 0 .

\section{Conclusions}

A rational assignment and an efficient use of radio spectrum have become sine qua non condition for the ICT sector development. Moreover, the consequences of the decisions about spectrum planning and management go beyond the sector. The innovation introduced in ICT markets regarding new services and applications hugely depends on the evolution of wireless technologies, which is reliant on the availability of spectrum. The knock-on effects, undoubtedly, will affect general users and, particularly, business organisations for which communications services are becoming a key strategic asset, no matter the particular sector of economic activity.

In this sense, the allocation of the digital dividend is one of the most relevant events among those that will have a global impact on the whole ICT sector in the near future. The value of the UHF band and the potentially high number of licences and interested bidders are proof of this. Therefore, what is at stake is of no little importance. Without ignoring television, the decision can condition a country's development of $B 3 \mathrm{G}$ or $4 \mathrm{G}$ technologies (and, therefore, the availability of ubiquitous broadband connectivity), what could position it in a situation of disadvantage against whatever neighbours may have chosen a dividend allocation more favourable to innovation.

Governments seem to become increasingly aware of this fact and, as time goes by, there is a stronger inclination to free-up a part of the dividend for services other than television. As an example, that of some European countries (Spain), which, having initially reserved all the UHF spectrum for television channels and not expecting to obtain any dividend, are now aligning themselves with the Commission's proposal of freeing-up the ' $800 \mathrm{MHz}$ band'.

This fact, added to the progressive replacement of the beauty contest with the auction as the preferred spectrum-allocation method, will result in the number of spectrum auctions undoubtedly increasing in the next years. Therefore, knowing how these auctions operate will be essential both for the industry's agents (and quite specifically, for mobile communication companies) and for governments. Academic research should contribute to this mission and this has been the main motivation for this work.

In this context, the simulation of a digital dividend auction with different sizes of digital dividend becomes a highly interesting first issue. The amount fixed for the dividend in different countries throughout the world is contained in a range that covers approximately from $50 \mathrm{MHz}$ to $120 \mathrm{MHz}$. As a consequence, three different scenarios 
using the extreme values of the bracket as well as a central one $(48 \mathrm{MHz}, 80 \mathrm{MHz}$ and $120 \mathrm{MHz}$ ) have been simulated.

The results show, as was to be expected, that the income per lot is maximised when the spectrum is scarcer. Additionally, and also logically, the sale of a greater amount of spectrum provides for a greater sharing out of the lots among the different bidders. It should be noted that, even in the scenario where the greater amount of spectrum is auctioned, television operators hardly win any lot. This implies that reserving a portion of the spectrum in the auction (spectrum caps) in favour of mobile communications would not change the results significantly, being those results quite similar to those of a service-neutral auction. A different matter would be if the spectrum caps where imposed to favour specific technological options or particular mobile services or applications. These research findings cannot be compared with those of other investigators as no similar studies have been found.

The present research has limitations and also possibilities of extension. Obviously, the specific numerical results depend on the allocated valuations, which, although based on a solid Ofcom report, would depend, in a real auction, on the specific conditions of the country, the market situation and the general economic climate at the time. Concerning other lines of research, it would be interesting to assess what the case would be should some of the agents use strategies in the auction such as 'market closure', trying to monopolise all the spectrum they could to reduce the chances for competitors. It would also be useful to know how the results change when the dividend is sold in two auctions separated in time (for example, as the appropriate channels are actually freed-up) instead of just a single auction.

Despite the above, the conclusions obtained seem relevant for anticipating some of the results of what will become the usual practice of the telecommunications industry during the next years. A usual practice, let us not forget it, extremely relevant for the future of mobile communications and the overall economy.

\section{Acknowledgement}

This paper has been financed by the Spanish research MCyT project MSTAR, Ref: TIN2008-06491-C04-03/TIN

\section{References}

Analysys Mason, DotEcon and Hogan\&Hartson (2009) Exploiting the Digital Dividend - A European Approach, Report 13496-336. Obtained through the intemet: http//www. analysysmason.com/PageFiles/13825/Analysys $\% 20 \mathrm{Mason} \% 27 \mathrm{~s} \% 20 \mathrm{final} \% 20 \mathrm{report} \% 20 \% 27 \mathrm{E}$ xploiting $\% 20$ the $\% 20$ digital\%20dividend $\% 20-\% 20 a \% 20$ European $\% 20$ approach $\%$ $27 \% 2020090814$.pdf

Ausubel, L.M., Cramton, P., McA fee, P. and McMillan, J. (1997) 'Synergies in wireless telephony: evidence from the broadband PCS auctions, Joumal of Econonics and Managentent Strategy, Vol. 6, No. 3, pp.497-527.

Avenali, A, and Bassanini, A. (2007) 'Simulating combinatorial auctions with dominance requirement and loll bids through automated agents', Decision Support Systems, Vol. 43, No. 1, pp.211-228. 
Bajari, P. and Yeo, J. (2009) 'Auction design and tacit collusion in FCC spectrum auctions', Information Economics and Policy, Vol. 21, No. 2, pp.90-100.

Banks, J., Olson, M., Porter, D., Rassenti, S. and Smith, V. (2003) 'Theory, experimental and the Federal Communications Commission spectrum auctions', Joumal of Economic Behaviour and Organization, Vol. 51, No. 3, pp.303-350.

Bazelon, C. (2009) 'Too many goals: problems with the $700 \mathrm{MHz}$ auction', Information Economics and Policy, Vol. 21, No. 2, pp.115-127.

BIPE Consulting (2002) Digital Switchover in Broadcasting, Study for the European Commission, Obtained through the intemet: http//ec.europa.eu/information_society/topics/telecoms/ regulatory/studies/documents/final_report_120402.pdf

Bykowsky, M.M., Olson, M. and Sharkey, W.W. (2010) 'Efficiency gains from using a market approach to spectrum management', Information Economics and Policy, Vol. 22, No. 1, pp.73-90.

Chong, A.Y.L., Damawan, N., Ooi, K.B. and Lin, B. (2010) "Adoption of 3G services among Malaysian consumers: an empirical analysis', International Joumal of Mobile. Conmunications, Vol. 8, No. 2, pp.129-149.

Cramton, P. (2007) 'How best to auction oil rights?', in Humphreys, M., Sachs, J.D. and Stiglitz, J.E. (Eds.): Escaping the Resource Curse, Columbia University Press, New York, pp.114-151.

Feijoo, C., Gómez-Barroso, I.L. and Mochón, A. (2009) 'Reforms in spectrum management policy', in Lee, I. (Ed.): Handbook of Research on Telecommumications Planming and Management for Business, IGI Global, Hershey - London, pp.33-47.

Hart, P.E., Nilsson, N.J. and Raphael, B. (1968) 'A formal basis for the heuristic determination of minimum cost paths', IEEE Transactions on Sustems Science and Cubenetics, Vol. 4, No. 2 , pp. $100-107$.

Karaiskos, D.C., Bina, M. and Giaglis, G.M. (2008) 'Insights on the drivers and inhibitors of mobile data services uptake', Intenational Joumat of Mobile Communications, Vol. 6, No. 3, pp.296-308.

Kim, K.Y., Yun, D.K. and Kim, D.Y. (2009) 'Expectations measurements in mobile data service: a case study', Intemational Joumal of Mobile Communications, Vol. 7, No. 1 , pp.91-116.

Liu, M.T., Huang, L.L. and Chen, A.N.C. (2008) 'Chinese consumer's adoption intention towards $3 \mathrm{G}$ mobile phone', International Joumal of Mobile Communications, Vol. 6, No. 6, pp. $770-786$

Melody, W.H. (2001) 'Spectrum anctions and efficient resource allocation: learning from the $3 \mathrm{G}$ experience in Europe', Info, Vol, 3, No. 1, pp.5-10.

Ofcom (2006) Digital Dividend Review - Document Consulting on the Proposed Approach to the Award of the Digital Dividend Spectrum $(470-862 \mathrm{MHz})$. United Kingdom Office of Communications. Obtained through the internet: http:/www.ofcom.org.uk/consult/condocs/ ddr/ddrmain.pdf

Ofcom (2007) Digital Dividend Review - A Statement on our Approach to Awarding the Digital Dividend, United Kingdom Office of Communications, Obtained through the intemet: http://www.ofcom.org.uk/consult/condocs/ddr/statement/statement.pdf

Plot, C.R. and Salmon, T.C. (2004) 'The simultaneous ascending auction: dynamics of price adjustment in experiments and in the UK $3 \mathrm{G}$ spectrum anction', Joumal of Economic Behaviour and Organization, Vol. 53, No. 3, pp.353-383.

Reeves, D.M., Wellman, M.P., MacKie-Mason, J.K. and Osepayshvili, A. (2005) 'Exploring bidding strategies for market-based scheduling', Decision Suppont Systems, Vol. 53, No. 1, pp.67-85. 
Sáez, Y., Mochón, A., Gómez-Barroso, J.L. and Isasi, P. (2008) 'Testing BOI and BOB algorithms for solving the winner determination problem in radio spectrum auctions', Proceedings of the 8th International Conference on Hybrid Intelligent Systems (HIS 2008), IEEE Computer Society Press, Barcelone, pp.732-737.

Stone, P., Schapire, R.E., Littman, M.L., Csirik, J.A. and McAllester, D. (2003) 'Decision-theoretic bidding based on learned density models in simultaneous, interacting anctions', Joumal of Artificial Intelligence Research, Vol. 19, No. 1, pp.209-242.

Wang, S. and Barnes, S.J. (2009) 'An analysis of the potential for mobile auctions in China', Intenational Joumal of Mobile Communications, Vol. 7, No. 1, pp.36-49.

\section{Annex I}

Definition of the services considered for spectrum valuations:

- DTT-SD: Companies interested in launching a new multiplex dedicated to additional standard definition digital television services.

- $\quad$ DTT-HD: Same, but high definition services

- Mobile multimedia: Companies interested in delivering a range of services to handheld devices. These could include data, music and services such as mobile TV.

- Mobile data centric: Companies interested in rolling out a broadband service using a newer technology (e.g. variants of the already used $3 \mathrm{G}$ standards, mobile WiMAX or even LTE or mobile ultrabroadband).

- Mobile voice and data: Companies interested in acquiring spectrum to augment current $3 \mathrm{G}$ services that focus on both voice and data

Tables 4 and 5 present the main characteristics of the Ofcom scenarios from which the bidders" values intervals are derived.

Table 4 Overview of the DTT economic modelling

\begin{tabular}{|c|c|c|c|c|}
\hline \multirow[b]{2}{*}{ Scenarios } & \multicolumn{2}{|c|}{$D T T-S D$} & \multicolumn{2}{|c|}{$D T T-H D$} \\
\hline & Low value & High value & Low value & High value \\
\hline $\begin{array}{l}\text { Ofcom value (fbn) } \\
\text { (producer }+ \text { consumer } \\
\text { value) }\end{array}$ & 0.5 & 3 & 1 & 3.5 \\
\hline Number of agents & 1 & 2 & 1 & 2 \\
\hline Spectrum acquired & 1 multiplex & 2 multiplex & 1 multiplex & 2 multiplex \\
\hline Main characteristics & $\begin{array}{l}\text { Low demand for } \\
\text { incremental } \\
\text { channels }\end{array}$ & $\begin{array}{l}\text { High demand for } \\
\text { incremental channels }\end{array}$ & $\begin{array}{l}\text { Low value of } \\
\text { HD channels }\end{array}$ & $\begin{array}{l}\text { High demand for } \\
\text { HD chamels }\end{array}$ \\
\hline \multirow[t]{2}{*}{ 'Adapted' value (EM) } & Min & $\operatorname{Max}$ & Min & $\operatorname{Max}$ \\
\hline & 185 & 556 & 371 & 649 \\
\hline
\end{tabular}


Table 5 Overview of the mobile economic modelling

\begin{tabular}{|c|c|c|c|c|c|c|}
\hline \multirow[b]{2}{*}{ Scenarios } & \multicolumn{2}{|c|}{ Mobile multimedia } & \multicolumn{2}{|c|}{ Mobile - voice and data } & \multicolumn{2}{|c|}{ Mobile - data centric } \\
\hline & Low value & High value & Low value & High value & Low value & High value \\
\hline $\begin{array}{l}\text { Ofcom value } \\
\text { (Ebn) (producer } \\
+ \text { consumer } \\
\text { value) }\end{array}$ & 0.3 & 3 & 0.5 & 2 & 1 & 2.5 \\
\hline Number of agents & 2 & 2 & 3 & 3 & 2 & 2 \\
\hline $\begin{array}{l}\text { Spectrum } \\
\text { required }\end{array}$ & $\begin{array}{c}24 \text { mobile } \\
\text { TV } \\
\text { channels }\end{array}$ & $\begin{array}{l}24 \text { mobile } \\
\text { TV channels }\end{array}$ & $10 \mathrm{MHz}$ & $10 \mathrm{MHz}$ & $24 \mathrm{MHz}$ & $24 \mathrm{MHz}$ \\
\hline $\begin{array}{l}\text { Main } \\
\text { characteristics }\end{array}$ & $\begin{array}{l}\text { Niche } \\
\text { market. } \\
\text { Urban } \\
\text { areas }\end{array}$ & $\begin{array}{l}\text { High } \\
\text { demand. } \\
\text { Some } \\
\text { adoption } \\
\text { delay }\end{array}$ & $\begin{array}{l}\text { Operators } \\
\text { possess } \\
\text { some } \\
900 \mathrm{MHz} \\
\text { spectrum }\end{array}$ & $\begin{array}{l}\text { First low } \\
\text { frequency } \\
\text { spectrum } \\
\text { (below } \\
1 \mathrm{GHz} \text { ) }\end{array}$ & $\begin{array}{l}\text { Moderate } \\
\text { demand. } \\
\text { Incumbents. } \\
\text { Available sites }\end{array}$ & $\begin{array}{c}\text { High } \\
\text { demand. } \\
\text { New } \\
\text { entrants. } \\
\text { No sites }\end{array}$ \\
\hline \multirow{2}{*}{$\begin{array}{l}\text { 'Adapted' value } \\
\text { (€M) }\end{array}$} & Min & Max & Min & $\operatorname{Max}$ & Min & Max \\
\hline & 56 & 556 & 62 & 247 & 185 & 463 \\
\hline
\end{tabular}

Table 6 present complement and substitution effects between lots and the resultant coefficient factor that multiplies values obtained for the optimum number of lots.

Table 6 Complement and substitution effects between lots and multiplication coefficients

\begin{tabular}{|c|c|c|c|c|c|c|c|c|c|c|}
\hline & \multicolumn{2}{|c|}{$D T T-S D$} & \multicolumn{2}{|c|}{$D T T \neg S D$} & \multicolumn{2}{|c|}{$\begin{array}{c}\text { Mobile } \\
\text { multimedia }\end{array}$} & \multicolumn{2}{|c|}{$\begin{array}{c}\text { Mobile - voice } \\
\text { and data }\end{array}$} & \multicolumn{2}{|c|}{$\begin{array}{l}\text { Mobile - data } \\
\text { centric }\end{array}$} \\
\hline $\begin{array}{l}\text { Number } \\
\text { of lots }\end{array}$ & $\begin{array}{l}\text { Value of } \\
\text { the lot }\end{array}$ & $\begin{array}{l}\text { Multipl. } \\
\text { coeff }\end{array}$ & $\begin{array}{l}\text { Value of } \\
\text { the lot }\end{array}$ & $\begin{array}{l}\text { Multipl. } \\
\text { coeff. }\end{array}$ & $\begin{array}{l}\text { Falue of } \\
\text { the lot }\end{array}$ & $\begin{array}{l}\text { Multipl. } \\
\text { coeff. }\end{array}$ & $\begin{array}{c}\text { Value of } \\
\text { the lot }\end{array}$ & $\begin{array}{l}\text { Multipl. } \\
\text { coeff. }\end{array}$ & $\begin{array}{c}\text { Value of } \\
\text { the lot }\end{array}$ & $\begin{array}{l}\text { Multipl. } \\
\text { coeff. }\end{array}$ \\
\hline 1 & & & & & 0.75 & 0.375 & 0.80 & 0.400 & 0.50 & 0.167 \\
\hline 2 & & & & & 1.00 & 1.000 & 1.00 & 1.000 & 0.75 & 0.500 \\
\hline 3 & 0.40 & 0.200 & 0.25 & 0.125 & 0.80 & 1.400 & 0.80 & 1.400 & 1.00 & 1.000 \\
\hline 4 & 0.65 & 0.433 & 0.50 & 0.333 & 0.60 & 1.700 & 0.60 & 1.700 & 0.90 & 1.300 \\
\hline 5 & 0.85 & 0.708 & 0.75 & 0.625 & 0.40 & 1.900 & 0.40 & 1.900 & 0.80 & 1.567 \\
\hline 6 & 1.00 & 1.000 & 1.00 & 1.000 & 0.20 & 2.000 & 0.20 & 2.000 & 0.70 & 1.800 \\
\hline 7 & 0.90 & 1.150 & 0.95 & 1.158 & & & 0.10 & 2.050 & 0.50 & 1.967 \\
\hline 8 & 0.80 & 1.283 & 0.90 & 1.308 & & & 0.05 & 2.075 & 0.25 & 2.050 \\
\hline 9 & 0.65 & 1.392 & 0.85 & 1.450 & & & & & & \\
\hline 10 & 0.50 & 1.475 & 0.75 & 1.575 & & & & & & \\
\hline 11 & 0.35 & 1.533 & 0.65 & 1.683 & & & & & & \\
\hline 12 & 0.20 & 1.567 & 0.55 & 1.775 & & & & & & \\
\hline 13 & & & 0.40 & 1.842 & & & & & & \\
\hline 14 & & & 0.25 & 1.883 & & & & & & \\
\hline 15 & & & 0.10 & 1.900 & & & & & & \\
\hline
\end{tabular}




\section{Annex II}

\section{Scenario A (6 lots)}

Frequency of lots earned by each bidder

\begin{tabular}{rrrrrrrrrrrrrrrr}
\hline & $B 1$ & $B 2$ & $B 3$ & $B 4$ & $B 5$ & $B 6$ & $B 7$ & $B 8$ & $B 9$ & $B 10$ & $B 11$ & $B 12$ & $B 13$ & $B 14$ & $B 15$ \\
\hline 0 & 100 & 100 & 100 & 45 & 100 & 44 & 83 & 93 & 100 & 100 & 96 & 98 & 87 & 88 & 27 \\
1 & 0 & 0 & 0 & 7 & 0 & 8 & 6 & 5 & 0 & 0 & 3 & 0 & 0 & 4 & 5 \\
2 & 0 & 0 & 0 & 30 & 0 & 24 & 9 & 2 & 0 & 0 & 1 & 0 & 0 & 6 & 24 \\
3 & 0 & 0 & 0 & 11 & 0 & 19 & 0 & 0 & 0 & 0 & 0 & 1 & 5 & 2 & 22 \\
4 & 0 & 0 & 0 & 6 & 0 & 4 & 1 & 0 & 0 & 0 & 0 & 1 & 7 & 0 & 19 \\
5 & 0 & 0 & 0 & 1 & 0 & 1 & 0 & 0 & 0 & 0 & 0 & 0 & 0 & 0 & 2 \\
6 & 0 & 0 & 0 & 0 & 0 & 0 & 1 & 0 & 0 & 0 & 0 & 0 & 1 & 0 & 1 \\
7 & 0 & 0 & 0 & 0 & 0 & 0 & 0 & 0 & 0 & 0 & 0 & 0 & 0 & 0 & 0 \\
8 & 0 & 0 & 0 & 0 & 0 & 0 & 0 & 0 & 0 & 0 & 0 & 0 & 0 & 0 & 0 \\
& 100 & 100 & 100 & 100 & 100 & 100 & 100 & 100 & 100 & 100 & 100 & 100 & 100 & 100 & 100 \\
\hline
\end{tabular}

Price paid per lot $(\in M)$

\begin{tabular}{lrrrrrrrrr}
\hline & $B 4$ & $B 6$ & \multicolumn{1}{c}{$B 7$} & \multicolumn{1}{c}{$B 8$} & \multicolumn{1}{c}{$B 11$} & $B 12$ & $B 13$ & $B 14$ & $B 15$ \\
\hline Mean & 144.0 & 146.8 & 108.4 & 84.3 & 76.62 & 105.6 & 117.3 & 103.7 & 173.3 \\
Stand. dev. & 30.4 & 26.7 & 15.0 & 16.7 & 30.1 & 14.4 & 14.1 & 16.4 & 37.1 \\
Max & 188.4 & 188.6 & 133.4 & 109.1 & 109.8 & 115.8 & 135.1 & 129.7 & 231.1 \\
Min & 68.0 & 68.8 & 73.7 & 54.2 & 44.5 & 95.4 & 81.1 & 79.2 & 63.5 \\
\hline
\end{tabular}

Seller's income ( $(\mathrm{M})$

\begin{tabular}{lrc}
\hline & Total & Per lot \\
\hline Mean & 904.6 & 150.8 \\
Stand. dev. & 141.0 & 23.5 \\
Max & 1188.9 & 198.1 \\
Min & 530.9 & 88.5 \\
\hline
\end{tabular}

\section{Scenario B (I0 lots)}

Frequency of lots earned by each bidder

\begin{tabular}{rrrrrrrrrrrrrrrr}
\hline & $B 1$ & $B 2$ & $B 3$ & $B 4$ & $B 5$ & $B 6$ & $B 7$ & $B 8$ & $B 9$ & $B 10$ & $B 11$ & $B 12$ & $B 13$ & $B 14$ & $B 15$ \\
\hline 0 & 100 & 100 & 100 & 32 & 100 & 38 & 64 & 78 & 100 & 98 & 84 & 87 & 73 & 68 & 17 \\
1 & 0 & 0 & 0 & 3 & 0 & 4 & 8 & 11 & 0 & 0 & 10 & 0 & 0 & 5 & 3 \\
2 & 0 & 0 & 0 & 27 & 0 & 24 & 21 & 8 & 0 & 0 & 3 & 0 & 1 & 17 & 13 \\
3 & 0 & 0 & 0 & 20 & 0 & 23 & 3 & 2 & 0 & 0 & 2 & 10 & 13 & 6 & 31 \\
\hline
\end{tabular}


Frequency of lots eamed by each bidder (continued)

\begin{tabular}{rrrrrrrrrrrrrrrr}
\hline & $B 1$ & $B 2$ & $B 3$ & $B 4$ & $B 5$ & $B 6$ & $B 7$ & $B 8$ & $B 9$ & $B 10$ & $B 11$ & $B 12$ & $B 13$ & $B 14$ & $B 15$ \\
\hline 4 & 0 & 0 & 0 & 13 & 0 & 11 & 4 & 1 & 0 & 0 & 1 & 2 & 10 & 4 & 27 \\
5 & 0 & 0 & 0 & 5 & 0 & 0 & 0 & 0 & 0 & 0 & 0 & 1 & 1 & 0 & 8 \\
6 & 0 & 0 & 0 & 0 & 0 & 0 & 0 & 0 & 0 & 1 & 0 & 0 & 2 & 0 & 1 \\
7 & 0 & 0 & 0 & 0 & 0 & 0 & 0 & 0 & 0 & 1 & 0 & 0 & 0 & 0 & 0 \\
8 & 0 & 0 & 0 & 0 & 0 & 0 & 0 & 0 & 0 & 0 & 0 & 0 & 0 & 0 & 0 \\
& 100 & 100 & 100 & 100 & 100 & 100 & 100 & 100 & 100 & 100 & 100 & 100 & 100 & 100 & 100 \\
\hline
\end{tabular}

Price paid per lot (€M)

\begin{tabular}{lrrrrrrrrrr}
\hline & $B 4$ & $B 6$ & $B 7$ & $B 8$ & $B 10$ & $B 11$ & $B 12$ & $B 13$ & $B 14$ & $B 15$ \\
\hline Mean & 139.7 & 137.1 & 105.5 & 80.5 & 84.1 & 79.2 & 106.8 & 114.9 & 109.7 & 160.3 \\
Stand. dev. & 26.4 & 29.8 & 19.8 & 12.7 & 1.7 & 13.1 & 8.9 & 13.3 & 19.3 & 38.2 \\
Max & 185.2 & 191.7 & 136.1 & 102.2 & 85.3 & 102.1 & 116.9 & 134.9 & 137.3 & 230.4 \\
Min & 64.0 & 56.7 & 51.0 & 62.2 & 83.0 & 56.0 & 92.6 & 92.9 & 65.0 & 45.7 \\
\hline
\end{tabular}

Seller's income ( $(\mathrm{M})$

\begin{tabular}{lrr}
\hline & Total & Per lot \\
\hline Mean & 1343.7 & 134.4 \\
Stand. dev. & 171.2 & 17.1 \\
Max & 1725.4 & 172.5 \\
Min & 932.5 & 93.3 \\
\hline
\end{tabular}

Scenario C (15 lots)

Frequency of lots earned by each bidder

\begin{tabular}{rrrrrrrrrrrrrrrr}
\hline & $B 1$ & $B 2$ & $B 3$ & $B 4$ & $B 5$ & $B 6$ & $B 7$ & $B 8$ & $B 9$ & $B 10$ & $B 11$ & $B 12$ & $B 13$ & $B 14$ & $B 15$ \\
\hline 0 & 100 & 99 & 100 & 32 & 100 & 20 & 52 & 74 & 100 & 93 & 76 & 76 & 47 & 55 & 13 \\
1 & 0 & 0 & 0 & 1 & 0 & 1 & 1 & 5 & 0 & 0 & 2 & 0 & 0 & 4 & 0 \\
2 & 0 & 0 & 0 & 15 & 0 & 25 & 21 & 10 & 0 & 0 & 16 & 0 & 0 & 27 & 13 \\
3 & 0 & 0 & 0 & 27 & 0 & 30 & 12 & 5 & 0 & 0 & 6 & 12 & 25 & 9 & 20 \\
4 & 0 & 0 & 0 & 21 & 0 & 19 & 6 & 0 & 0 & 0 & 0 & 8 & 18 & 4 & 37 \\
5 & 0 & 0 & 0 & 4 & 0 & 3 & 6 & 6 & 0 & 0 & 0 & 3 & 4 & 1 & 15 \\
6 & 0 & 0 & 0 & 0 & 0 & 2 & 2 & 0 & 0 & 6 & 0 & 1 & 3 & 0 & 2 \\
7 & 0 & 1 & 0 & 0 & 0 & 0 & 0 & 0 & 0 & 0 & 0 & 0 & 3 & 0 & 0 \\
8 & 0 & 0 & 0 & 0 & 0 & 0 & 0 & 0 & 0 & 1 & 0 & 0 & 0 & 0 & 0 \\
& 100 & 100 & 100 & 100 & 100 & 100 & 100 & 100 & 100 & 100 & 100 & 100 & 100 & 100 & 100 \\
\hline
\end{tabular}


Price paid per lot (EM)

\begin{tabular}{lccccccccccr}
\hline & $B 2$ & $B 4$ & $B 6$ & \multicolumn{1}{c}{$B 7$} & $B 8$ & $B 10$ & $B 11$ & $B 12$ & $B 13$ & $B 14$ & $B 15$ \\
\hline Mean & 78.4 & 139.2 & 137.0 & 109.8 & 91.5 & 94.5 & 92.2 & 104.5 & 114.8 & 101.9 & 159.2 \\
Stand. dev. & & 25.3 & 28.1 & 14.2 & 29.1 & 3.9 & 30.1 & 10.3 & 31.1 & 18.1 & 32.1 \\
Max & 78.4 & 185.6 & 191.7 & 136.7 & 107.2 & 97.3 & 109.8 & 117.5 & 136.5 & 135.1 & 211.9 \\
Min & 78.4 & 67.1 & 63.8 & 74.2 & 51.7 & 86.2 & 44.5 & 70.5 & 87.5 & 57.6 & 97.2 \\
\hline
\end{tabular}

Seller's income ( $€ \mathrm{M})$

\begin{tabular}{lcc}
\hline & Total & Perlot \\
\hline Mean & 1927.6 & 128.5 \\
Stand. dev. & 215.8 & 14.5 \\
Max & 2473.6 & 164.9 \\
Min & 1310.5 & 87.4 \\
\hline
\end{tabular}

